\title{
Collateral Circulation of the Liver Functional and Clinical Studies
}

\author{
Shozo NAKAMURA \\ The First Department of Internal Medicine, Tohoku University \\ School of Medicine, Sendai
}

Porto-caval and porto-pulmonary anastomoses are main collaterals concerning the liver, and have great clinical significances. These collaterals are deemed also shunted pathways of the liver. There is another shunted pathway, namely, intrahepatic shunt. The purpose of the present studies is to determine the blood flow through the extrahepatic collaterals in liver cirrhosis by a new method, and to elucidate clinical significances of the extrahepatic collateral (shunted) blood flow, as compared with the intrahepatic shunted blood flow.

\section{1) New method of measurement of the extrahepatic collateral (shunted) blood flow}

In 1959, a method of measurement of the extrahepatic collateral (shunted) blood flow was first devised by us.1) In the method, the extrahepatic collateral (shunted) blood flow was calculated from the radioactivity curve of the brachial arterial blood after the intrasplenic injection of radioactive iodinated human serum albumin. Thereafter, another method of measurement of the extrahepatic collateral blood flow was reported by Iber et al. ${ }^{2}$. In this method the extrahepatic collateral blood flow was calculated from the hepatic blood flow and the hepatic venous and femoral arterial radioactivity after the injection of radioactive iodinated human serum albumin into the spleen. There is, however, considerable difference between the results by the both methods. Hence, we have undertaken to examine the propriety of the methods by comparing the results by a new method devised on a basis of a different principle with those by our previous method and Iber's method. Moreover, we have attempted to estimate the extrahepatic collateral (shunted) blood 
flow core simply and exactly by the new method.

Method: After a solution of T-1824 or Cardio-green is injected intravenously, a dye concentration curve is obtained with an ear densitometer. Cardiac output $(\mathrm{Q}, \mathrm{L} . / \mathrm{min}$.) is calculated according to the following equation:

$$
\mathrm{Q}=\frac{60 \mathrm{I}}{\overline{\mathrm{e}}_{1} \mathrm{~T}_{1}}
$$

where $I=$ quantity of $\mathrm{T}-1824$ or Cardio-green injected, in $\mathrm{mg}$.

$\overline{\mathrm{c}}_{1}=$ average concentration of the first peak, in $\mathrm{mg} . / \mathrm{L}$.

$\mathrm{T}_{1}=$ passage time of the first peak, in sec.

Secondly, the same quantity of T-1824 or Cardio-green is injected into the spleen, and a dye concentration curve is drawn similarly. When there is extrahepatic collateral (shunted) blood flow, a part of the injected dye goes through the shunt and appears in the dye concentration curve earlier than the dye flowing through the liver. Cardiac output (Q, L./min.) is calculated from average dye concentration of the peak due to the extrahepatic collateral (shunted) blood flow $\left(\overline{\mathrm{c}}_{2}, \mathrm{mg} . / \mathrm{L}.\right)$, passage time $\left(\mathrm{T}_{2}\right.$, sec.), and quantity of the dye flowing through the extrahepatic collateral ( $\mathrm{I}_{\mathrm{S}}, \mathrm{mg}$.):

$$
\mathrm{Q}=\frac{60 \mathrm{I}_{\mathrm{S}}}{\overline{\mathrm{c}}_{2} \mathrm{~T}_{\mathrm{S}}}
$$

Then

$$
\frac{\mathrm{I}_{\mathrm{S}}}{\mathrm{I}}=\frac{\overline{\mathrm{c}}_{2} \mathrm{~T}_{2}}{\mathrm{c}_{1} \mathrm{~T}_{1}}
$$

When radioactive iodinated human serum albumin is injected into the vein and into the spleen simultaneously with the dye, the ratio of quantity of dye flowing into the peripheral vein ( $\mathrm{I}, \mathrm{mg}$.) to that flowing into the splenic vein ( $\mathrm{I}^{\prime}, \mathrm{mg}$.) is calculated from the radioactivity of the brachial arterial blood obtained 2 minutes after the intravenous injection $\left(\mathrm{C}_{1}\right.$, counts) and that after the intrasplenic injection $\left(\mathrm{C}_{2}\right.$, counts $)$ :

$$
\frac{\mathrm{I}}{\mathrm{I}^{\prime}}=\frac{\mathrm{C}_{1}}{\mathrm{C}_{2}}
$$

As ratio of the extrahepatic collateral (shunted) blood flow to the total portal blood flow is considered to be $\frac{I_{3}}{I^{\prime}}$, per cent extra- 
hepatic shunt $\left(\mathrm{P}_{\mathrm{ex}}\right)$ is calculated as follows:

$$
\begin{aligned}
\mathrm{P}_{\mathrm{ex}} & =\frac{\mathrm{I}_{\mathrm{S}}}{\mathrm{I}^{\prime}} \times 100 \\
& =\frac{\mathrm{I}_{\mathrm{S}}}{\mathrm{I}} \times \frac{\mathrm{I}}{\mathrm{I}^{\prime}} \times 100 \\
& =\frac{\overline{\mathrm{c}}_{2} \mathrm{~T}_{2}}{\overline{\mathrm{c}}_{1} \mathrm{~T}_{1}} \times \frac{\mathrm{C}_{1}}{\mathrm{C}_{2}} \times 100
\end{aligned}
$$

In this formula multiplication of $\frac{\mathrm{C}_{1}}{\mathrm{C}_{2}}$ is considered to be the correction to the stoppage of a part of the injected dye in the spleen. This correction is made by the injection of radioactive iodinated human serum albumin instead of $\mathrm{T}-1824$ or Cardio-green because therea is possibility of binding of the dye with proteins of liver cells. It is because continuous rocording of the dye concentration is easily done with the car densitometer that the calculation of $\frac{\bar{c}_{2}}{c_{1}} \frac{T_{2}}{T_{1}}$ is not made in the radioactivity curve of iodinated human serum albumin but in the dye concentration curve.

$\mathrm{T}-1824$ is injected in a dose of $20 \mathrm{mg}$, and Cardio-green in a dose of $5 \mathrm{mg}$. Both dyes are measured by means of a newly-devised ear densitometer in which cadmium sulfite photoconductive cell is used. Earpiece dye curves are calibrated by the one-point calibration method, namely, by a determination of dye concentration in a sample of peripheral blood withdrawn 2 minutes after the injection of the dye.

Results and Discussion: The results are shown in Fig. 1. The extrahepatic collateral (shunted) blood flow is observed in 6 out of 9 cases with liver cirrhosis, the maximal per cent extrahepatic shunt being 61 per cent. The average per cent extrahepatic shunt of the 9 cases with liver cirrhosis is 14 per cent. These results are almost the same as those measured by our previous method. However, some differences are observed between the results by the previous method and those by the new one, when the observations are made in the same individuals (Table 1). In some cases the presence of the extrahepatic collateral (shunted) blood flow is confirmed from the shortened spleen-brachial artery appearance time by the previous method, but is not quantitatively calculated because of undiffer- 


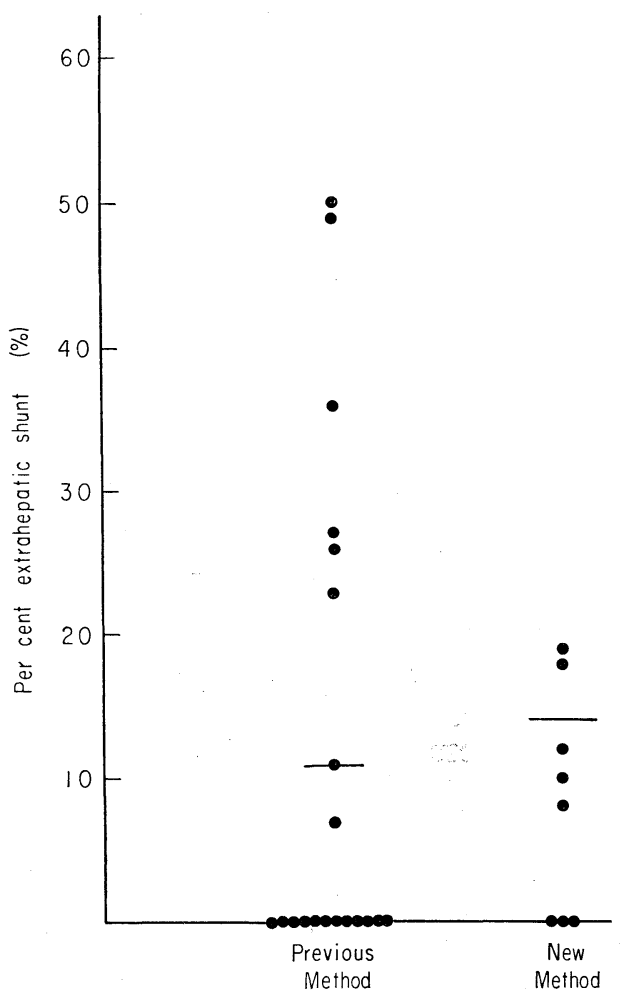

Fig. 1. Per cent extrahepatic shunt in liver cirrhosis.

Table 1. Comparison of Methods of Measurement of Extrahepatic Collateral (Shunted) Blood Flow in Liver Cirrhosis

\begin{tabular}{|c|c|c|c|c|c|}
\hline \multirow{3}{*}{ Patient } & \multirow{2}{*}{\multicolumn{3}{|c|}{$\left(\begin{array}{c}\text { extrahepatic collateral } \\
\text { blood flow } \\
\text { total portal blood flow }\end{array}\right)$}} & \multirow{3}{*}{$\begin{array}{c}\text { Esophageal } \\
\text { varices }\end{array}$} & \multirow{3}{*}{ Splenoportography } \\
\hline & & & & & \\
\hline & $\begin{array}{l}\text { Previous } \\
\text { method }\end{array}$ & $\begin{array}{l}\text { New } \\
\text { method }\end{array}$ & $\begin{array}{l}\text { Ib:r's } \\
\text { method }\end{array}$ & & \\
\hline & + & $19 \%$ & & + & Gastric coronary vein (mild) \\
\hline & $0 \%$ & $10 \%$ & & - & \\
\hline & $50 \%$ & $61 \%$ & & - & $\begin{array}{l}\text { Spleno-renal venous } \\
\text { anastomosis (moderate) }\end{array}$ \\
\hline & $0 \%$ & $0 \%$ & & - & \\
\hline & + & $8 \%$ & $64 \%$ & + & No collateral \\
\hline & $0 \%$ & $0 \%$ & $0 \%$ & - & \\
\hline & $0 \%$ & $12 \%$ & $36 \%$ & - & Gastric coronary vein (mild) \\
\hline & $0 \%$ & $0 \%$ & $69 \%$ & - & \\
\hline
\end{tabular}


entiation of the peak due to extrahepatic collateral (shunted) blood flow through the liver in the radioactivity curve. Even in such cases the two peaks are well differentiated by the new method and the per cent extrahepatic shunt can be calculated. There are also some cases in which the extrahepatic collateral (shunted) blood flow is not confirmed by the previous method because of small quantity but can be calculated by the new method. Thus the new method is more sensitive than the previous method.

There is considerable difference between the results obtained by Iber's method and those by our previous and new methods: in most cases per cent extrahepatic shunt estimated by Iber's method is larger than that by our methods.

According to Iber et al., ${ }^{2}$ the extrahepatic collateral blood flow is calculated after intrasplenic injection of radioactive iodinated human serum albumin from the equation:

$$
\text { Extrahepatic collateral blood flow }=\frac{Q_{\mathrm{col} 1}}{Q_{\mathrm{col1}}+\mathrm{Q}_{\mathrm{hv}}-\mathrm{Q}_{\mathrm{fa}}}
$$

where $Q_{\text {coll }}=$ radioactivity leaving by the collaterals during four and

a half minutes after the intrasplenic injection

$\mathrm{Q}_{\mathrm{hv}}=$ radioactivity leaving via the hepatic veins

$\mathrm{Q}_{\mathrm{f}}=$ radioactivity entering the splanchnic bed

In this equation substraction of radioactivity flowing in is made only in the denominator, but not in the numerator. Therefore, the extrahepatic collateral blood flow is naturally overestimated by Iber's method. This theoretical criticism is in accord with our observations.

The invalidity of Iber's method is also shown by splenoportography. Extrahepatic collateral cannot be found in the splenoportogram of a patient who shows 64 per cent of collateral blood flow by Iber's method. In another patient showing 36 per cent of collateral blood flow, only a slight collateral is found (Table 1). Thus Iber's method is considered to be inappropriate for the measurement of the extrahepatic collateral (shunted) blood flow.

On the other hand, almost the same results are obtained by both our previous and new methods. In animal experiment, it was shown that the per cent extrahepatic shunt measured by the previous method was in good accordance with the results obtained with flow meters. ${ }^{3)}$ There is no clinical data conflicting with the results ob- 
tained by our methods. Moreover, as will be stated later, our methods are clinically very useful. These facts show that our methods give a useful index for the quantitative estimation of the extrahepatic collateral (shunted) blood flow, though it is not absolutely perfect theoretically.

The absolute quantity of the extrahepatic collateral (shunted) blood flow (EHSBF) is calculated from the per cent extrahepatic shunt $\left(\mathrm{P}_{\mathrm{ex}}\right)$ and the portal blood flow (PBF) estimated by our method.4)

$$
\mathrm{EHSBF}=\mathrm{PBF} \times \frac{\mathrm{P}_{\mathrm{ex}}}{100-\mathrm{P}_{\mathrm{ex}}}
$$

The results are shown in Fig. 2. The extrahepatic collateral (shunted) blood flow in liver cirrhosis averages 45 c.c. $/ \mathrm{min} . / \mathrm{m}^{2}$, and is low as compared with the intrahepatic shunted blood flow. The intrahepatic shunted blood flow measured by galactose method ${ }^{5}$ averages 248 c.c. $/ \mathrm{min} . / \mathrm{m}^{2}$.

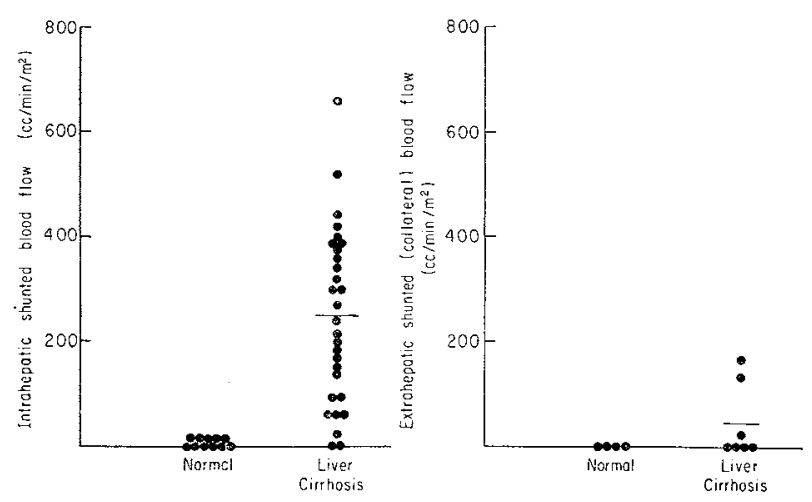

Fig. 2. Extrahepatic and intrahepatic shunted (collateral) blood flow in liver cirrhosis.

\section{2) Clinical significances of the extrahepatic collateral (shunted) blood flow}

For the purpose of elucidating the clinical significances of the extrahepatic collateral (shunted) blood flow, the relationship between the extrahepatic collateral (shunted) blood flow and clinical findings and laboratory tests in liver cirrhosis is investigated. 
Since there is significant positive correlation between the per cent extrahepatic shunt and the wedged hepatic venous pressure, it is suggested that portal hypertension plays an important role in the development of the extrahepatic collaterals. On the other hand, there is no significant correlation between the per cent intrahepatic shunt and the wedged hepatic venous pressure.

As for clinical findings, significant correlation is found only between the per cent extrahepatic shunt and esophageal varices and between the per cent extrahepatic shunt and splenomegaly.

In contrast to the per cent intrahepatic shunt which is well correlated with liver function tests, serum albumin concentration and serum gamma globulin concentration, the per cent extrahepatic shunt is not significantly correlated with these indices which reflect intrahepatic changes.

There is no significant correlation between the per cent extrahepatic shunt and the per cent intrahepatic shunt. However, an interesting relationship is found between the both per cent shunt and the morphological classification of liver cirrhosis.

Liver cirrhosis is morphologically classified into the following 3 types. ${ }^{6}$

Type I: There are broad connective tissue band due to massive liver cell necrosis. Regenerative nodules are variable in size and histologically multilobular or sublobular. Bizarre regeneration of liver cells is frequently observed.

Type II: The connective tissue bands are less than $3 \mathrm{~mm}$. in width. The regenerative nodules are uniform in size and mostly multilobular, measuring $4-10 \mathrm{~mm}$. in diameter.

Type III: The connective tissue bands are narrowest, and less than $1 \mathrm{~mm}$. in width. The nodules are histologically sublobular, having a diameter of less than $4 \mathrm{~mm}$. The changes are diffuse.

The per cent extrahepatic shunt is greater in Type II than in Type $I$, and the per cent intrahepatic shunt is greater in Type I than in Type II. Type III cannot be compared because of few cases to study. These facts as well as the fact that the wedged hepatic venous pressure is higher in Type I than in Type $I^{6)}$ show close relationship between morphological types and changes in hepatic circulation. It is natural that the per cent intrahepatic shunt is 
greater in Type I in which intrahepatic shunted pathways are presumably abundantly formed. The reason why the per cent extrahepatic shunt is greater in Type II is not yet clear. In Type II, extrahepatic collateral may develop to prevent progression of portal hypertension because of slight formation of intrahepatic shunt, or stenosis of intrahepatic portal trees may selectively occur.

As for changes in systemic circulation and respiration in liver cirrhosis, Heineman ${ }^{7}$ suggested an interesting hypothesis that pulmonary hypertension, decreased peripheral vascular resistance, increased cardiac output, and increased plasma volume seen in liver cirrhosis are all ascribed finally to increased extrahepatic collateral circulation. Anoxemia in liver cirrhosis is considered by some investigators to be caused by the porto-pulmonary anastomosis. Hence, we have investigated the relationship of the extra-and intrahepatic shunted blood flow to the changes in systemic circulation and respiration in liver cirrhosis.

Although increased plasma volume, increased cardiac output, decreased oxygen saturation of arterial blood, and decreased $\mathrm{CO}_{2}$ content are found in liver cirrhosis, there is significant correlation only between plasma volume and the per cent extrahepatic shunt. There is neither pulmonary hypertension nor increase of minute ventilation.

Oxygen saturation less than 94 per cent is found in 42 per cent of 33 cases. It seems to be improbable that the porto-pulmonary anastomosis causes decrease of oxygen saturation of arterial blood, since there is no significant relationship between spleen-brachial artery appearance time and oxygen saturation of arterial blood. This view is also supported by the calculation of the absolute quantity of the extrahepatic collateral (shunted) blood flow. The extrahepatic collateral (shunted) blood flow in liver cirrhosis, averaging 45 c.c./min./m. ${ }^{2}$, is too small to account for the decrease of oxygen saturation in liver cirrhosis.

As pulmonary function tests are almost normal except diffusing capacity and decreased oxygen saturation cannot be explained by decreased diffusing capacity, further studies are necessary to elucidate mechanism of decreased oxygen saturation in liver cirrhosis.

The relationship between the per cent extra- and intra-hepatic 

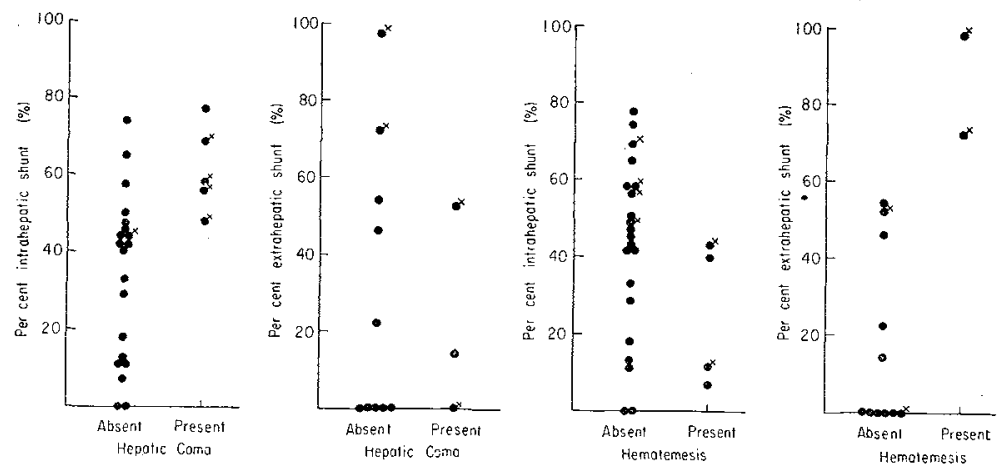

Fig. 3. Relationship between intra- and extra-hepatic shunted blood flow and prognosis in patients with liver cirrhosis who have been observed more than one year after the measurement.

shows death.

shunt and prognosis of liver cirrhosis is shown in Fig. 3. Hepatic coma and deaths from it occur in cases with high intrahepatic shunted blood flow, and esophageal bleeding and deaths from it are observed in cases with high extrahepatic shunted blood flow. The latter fact indicates that hepatic coma in liver cirrhosis is mainly caused by intrahepatic changes, and not by increased extrahepatic collateral (shunted) blood flow.

\section{Summary}

A new method was presented for the measurement of extrahepatic collateral (shunted) blood flow in liver cirrhosis. Per cent extrahepatic shunt averaged 14. per cent. The result was almost the same as that obtained by the previous method of the author. The extrahopatic collateral (shunted) blood flow calculated from the per cent extrahepatic shunted and the portal blood flow averaged 45 c.c. $/ \mathrm{min} . / \mathrm{m}^{2}$, and was considerably lower than the intrahepatic shunted blood flow. The relationship between the extrahepatic collateral (shunted) blood flow and clinical findings and laboratory tests was also described.

\section{References}

1) Nakamura, T., Nakamura, S., Tokita, K., Kaneko, T., Suzuki, T., Watanabe, M. and Sato, T.: Measurement of intrahepatic and extrahepatic shunted blood flow 
in cirrhosis of the liver. The First Meeting of Japanese Branch of International Association for the Study of the Liver, Sept. 20, 1959; Acta Hepatol. Jap. 1 (Suppl. 1) : $1-5,1960$.

2) Iber, F. L., Kerr, D. N. S., Dölle, W. and Sherlock, S.: Measurement of blood flow in the collateral vessels of the portal vein; preliminary results of a new method, J. Clin. Invest. 39 1201-1207, 1960.

3) Nakamura, T., Nakamura, S., Kaneko, T., Suzuki, T., Tokita, K., Sato. T. and Abe, S.: Studies on hepatic circulation in cirrhosis of the liver, Acta Heapatol. Jap. 2 (Suppl. 1) : 16-19, 1961.

4) Nakamura, T., Nakamura, S. and Kaneko, T.: Flow of portal and hepatic blood in normal and cirrhotic liver, Nature 190: 812-813, 1961.

5) Nakamura, T., Nakamura, S., Tokita, K., Watanabe, M., Sato, T., Suzuki, T. and Kaneko, T.: An approach to measurement of blood flow in intrahepatic shunts in cirrhosis of the liver, J. Lab. Clin. Med. 58:455-467, 1961.

6) Nakamura, T., Nakamura, S., Tokita, K., Suzuki, T., Kaneko, T. and Abe, S.: Classification of liver cirrhosis (Jap.), Saishin Igaku 16:166-187, 1961.

7) Heinemann, H. O.: Respiration and circulation in patients with portal cirrhosis of the liver, Circulation 22: 154-159, 1960. 